\title{
Creating Inclusive Spaces for Partnership

\author{
Responses from local leaders engaged in a \\ community-university partnership centre
}

\author{
Kara Mileski \\ Abdulkhaliq Mohamed \\ Rosemarie Hunter \\ University of Utah
}

Gateways: International Journal of Community Research and Engagement Vol 7 (2014): 144-156 (C) UTSePress and the authors

ISSN 1836-3393
Established in 2004, the Hartland Partnership Center is a community-university partnership offering programs to adults and youth living on the westside of Salt Lake City, Utah. According to Mai and Schmit (2013), westside neighbourhoods are home to the majority of individuals with refugee or immigrant backgrounds in Salt Lake County. The US Census Bureau (2010) reported that 83 per cent of the city's Pacific Islander population and 60.8 per cent of the city's African population live on the westside of Salt Lake City (as cited in Hunter and Mileski 2013). In addition to this, the Utah Refugee Coalition (2013) states that of the 46000 refugees resettled in Utah, with 1000 new arrivals each year, 99 per cent live in the Salt Lake valley (as cited in Hunter and Mileski 2013). Given the demographics in the surrounding neighbourhoods, the majority of the individuals accessing the services of the Hartland Partnership Centre are of refugee or immigrant background. The services offered are the result of the collaboration of eight community organisations and 10 university departments.

The Hartland Partnership Center brings together faculty, students, community agencies and residents to co-design and implement programs with the families living on the westside of Salt Lake City. The partners involved in the Center work together to build upon one another's strengths in an effort to facilitate programming that develops community capacity and helps to overcome economic, linguistic and social barriers experienced by new arriving communities of immigrant and refugee background and by families living in generational poverty. This asset-based, capacity-building model builds on the works of Kretzman and McKnight (1993), providing families with a comprehensive set of services and educational resources where they live. This model works because the resources fit the reality, and a culture of reciprocal learning permeates the Center. Within all of the 10 on-site partnerships, each person is valued for his/her knowledge and the partnerships strive to create a space of shared power (UNP 2014).

The Hartland Resident Committee (HRC) at the Hartland Partnership Center serves as a community board of advisers. The 
HRC informs the Hartland Partnership Center as to what services are needed in the community and provides valuable feedback to the partners with regard to offering/facilitating culturally informed services that address the priorities of the community. The HRC members are also engaged in conducting cultural presentations at local schools, community centres and social service organisations, and are invited to be guest speakers in undergraduate and graduate classes at the University of Utah. In conducting needs assessments, facilitating community meetings and participating in partnership teams, they are actively engaged in the development of services which meet the needs of diverse families in the community. The HRC members serve as a bridge between the community at large and partners from community organisations and higher education.

This article focuses on the motivation and leadership of the members of the Hartland Resident Committee. Building on the expertise of current and past HRC members, this pilot project was designed to examine the motivations for members to become involved with the HRC and to sustain participation over the long term, as well as investigating areas requiring improvement.

During 2012, a PhD social work student and an HRC member conducted six interviews to identify effective methods of engaging individuals in the community and working with members in a sustainable and participatory manner. Findings from this pilot study were implemented to improve the experience of HRC members and to create a more inclusive leadership model. This project also provided an opportunity to examine and delve deeper into the make-up of the HRC to understand more about how the committee has developed over time and what motivates members to remain engaged.

\section{THEORETICAL FOUNDATION}

Communities around the world are shifting focus and adapting as they face new and unexpected challenges. One of these challenges has been the generation of a culture of dependency arising from neo-liberal policies fostering hegemony (Cabezas, Reese \& Waller 2007; Farmer 2005). Charity models have failed to recognise the unique abilities of community members to inform policy development and positive social change (Cabezas, Reese \& Waller 2007). As Easterling and Millesen (2012, p. 20) say, 'Paternalism is no recipe for prosperity in the twenty-first century'.

Larger systems, built upon uneven power structures, ignore community input and leave communities vulnerable to shifts in policy (Finn \& Jacobson 2003; Gray \& Webb 2009). However, communities have the ability to inform growth and change within their own environment (Wheatley \& Frieze 2011).

Empowering communities builds their capacity and engages people and groups to challenge existing power dynamics. Empowerment places the individual and community practitioner in a position to challenge larger systems. A top-down approach, 
on the other hand, contributes to systems that hinder an individual's ability to function as an independent agent for change in their community (Gray \& Webb 2009). Through the lens of empowerment, community members are viewed as capable of becoming leaders in developing sustainable solutions, in spite of systemic challenges. Such leaders represent diversity, strength and experience. As a result, solutions are a creation of coming together and defining what works for their own communities (Ayon \& Lee 2009; Gutierrez et al. 1996).

Capacity building within communities is one way to build community leadership. Capacity building acknowledges that communities have many strengths and abilities that can be harnessed to address problems in the community (Kegler, Norton \& Aronson 2007). In doing so, community members emerge with multiple forms of knowledge and a multitude of skills that can contribute to developing a community leadership model (Moll \& González 1997). For example, as individuals engage in leadership skill-building activities they gain experience with grant writing, community organising, building social capital and accessing community resources (Easterling 2012; Neighborworks 2012).

Additionally, in building the capacity of local leaders, we bring the experience and knowledge of communities to the forefront. The definition of knowledge varies across and within communities. Within academic settings, knowledge is interpreted as dependent on level of education, whereas within community settings knowledge comes from life experiences. Knowledge becomes rich and sustainable when these two cultures of understanding integrate and combine to provide best practices for all stakeholder groups. To develop successful knowledge creation, both mainstream and newcomer communities must be involved in a dynamic, multi-directional process through consistent interaction (Bourhis et al. 1997).

\section{THE HARTLAND RESIDENT COMMITTEE}

The Hartland Partnership Center is one of 40 communityuniversity partnerships of University Neighborhood Partners (UNP), a department of the University of Utah. Founded in 2001, its mission is to bring together university and community resources for reciprocal learning, action and benefit: a community coming together (UNP 2014). Designed to locate power within the joined hands of community members and university affiliates, knowledge integration and building the capacity of community leaders are at the forefront of UNP's work (UNP 2014). In 2004, UNP started the Hartland Partnership Center in a three-bedroom apartment in Hartland Apartments (renamed Seasons at Pebble Creek in 2008). Serving as a gateway community for newly arriving populations of immigrant and refugee backgrounds, the complex is home to people from Africa, Central and South America, South East Asia and many other parts of the world. 
Ninety per cent of the community lives below the poverty threshold (Hunter et al. 2011). By creating a community-university partnership centre within the apartment complex, UNP sought to create a space for residents to develop their capacity to work within their own communities. Within the first year, and as a way to join with the community, the Hartland Partnership Center developed the Hartland Resident Committee, comprised of 10 residents of diverse backgrounds who provide leadership with regard to programming at the Center and serve as community liaisons and cultural consultants.

The Hartland Partnership Center offers numerous programs that promote reciprocal sharing and learning. The programs include language classes, citizenship classes, youth programs, legal education, health education and screenings, employment and life skills classes, and social work services. These activities are delivered through community-university partnership teams that include higher education institutions, community partners (notfor-profit organisations, local schools, government agencies) and resident partners. While many residents participate at the Center in a variety of roles (as participants, instructors, translators), the HRC members also participate in the Center's Steering Committee and are connected to each of the partnership teams. Members of the $\mathrm{HRC}$ receive stipends to support their participation in guiding these partnerships (Hunter et al. 2011).

In April 2013, UNP purchased a 930 square metre building adjacent to the apartment complex, and expanded its partnerships to include a women's health clinic (clinical site of the College of Nursing and Department of Midwifery) and a family counselling centre (existing community partner). The Center also expanded its geographical area to include the surrounding neighbourhoods.

Currently, the HRC is composed of eight individuals, who meet bi-weekly to discuss issues facing them and their communities. In these discussions, members develop solutions to these issues, as well as ways the partners can respond. These responses may take the form of developing a class for the community, writing a letter to a policy-maker, or visiting the home of one of the residents in the community. The responses are varied and effective.

Crosby et al. (2013) found that, in evaluating their own community-academic partnership in health, it was not until community leadership was developed that the partnership was able to address the needs of residents. Similarly, the formation of the HRC was designed to lead the partnership in order to meet the needs of the residents in their community.

Rather than creating programs for community members, engaging them in program development creates more effective involvement and contribution from community members (Fraenkel 2006). The HRC brings together multiple stakeholders to co-create programs that benefit all involved. They welcome and value newcomer communities as partners in knowledge creation. For 
example, when the Center was created, the first task was meeting with residents of the community to determine which programs would be most beneficial to them. The information gathered informed the initial direction of the Hartland Partnership Center, and today the HRC continues to develop, enhance and change the direction of programs at the Center as new community priorities emerge.

By examining the history of the HRC and interviewing HRC members, this study expands on the existing literature on community leadership. Capacity building and empowerment are critical steps in creating sustainable and positive change in our communities; and, in turn, empowerment affects individuals, families, communities and organisations (Prestby et al. 1990). However, once these systems are in place, what is it that encourages people to be involved and sustains their involvement? We sought to understand what it was about the organisation of the HRC, the community and individual experience that motivated members to remain engaged with their community over time. HRC members are members for at least one year, but often they remain members for several years, so we also looked at what it was that made them feel comfortable to contribute and share knowledge in this setting.

\section{METHOD}

\section{Participant characteristics}

Study participants included current and past members of the Hartland Resident Committee. Committee members are recognised as leaders representing their respective communities (ethnic and/ or geographic). Members are a combination of self-selected leaders, leaders selected by the community, or leaders identified by staff through their involvement at the Center and in the community.

This sample reflected the diversity of the HRC and was composed of 6 individuals, of which 4 were female and 2 were male. Ages ranged from 21 to 65, with a mean age of 43 . Participants had been living in Salt Lake City for between 4 and 15 years, with a mean of 10 years. Individuals were from various countries of origin. The countries represented in this sample were Sudan, Somalia, United States, Afghanistan and Iraq. All individuals spoke English.

As mentioned above, local residents are asked to serve on the committee for at least one year, although the majority of members continue to work on the $\mathrm{HRC}$ for longer. Our sample reflected this. Four participants were current HRC members and, of these, three had been on the HRC for just over one year, and one for four years. Two participants were previous committee members, who had been on the committee for three and seven years.

\section{Sampling procedures}

This was a convenience sample. Current or past participants were notified of this project via telephone, email or home visit. Of the eight committee members approached, six participated. All 
interviews were conducted at the Hartland Partnership Center; however, researchers offered to meet participants in any space that was convenient for them. The Hartland Partnership Center is centrally located and familiar to the participants.

Prior to conducting the interviews, participants were read a consent to participate letter. Interviewers chose to read the consent form with participants, as they were unsure of the English literacy level of all participants. This research was determined to be exempt by the University of Utah Institutional Review Board.

\section{Research design}

An informal script was developed for the initial contact with possible participants to ensure that all participants received the same information up-front. Interviewers also reviewed interviewing techniques together prior to interviewing members. Semi-structured interviews were then conducted with the six current and past committee members.

Before conducting the interviews, researchers and participants reviewed the consent cover letter. In an effort to ensure the form was understood, researcher and participant read through the letter together. Researchers explicitly stated that names and contact information would be withheld; and years served on the HRC would not be attached to an individual. Names in this article and other print material have been changed in an effort to ensure anonymity for the community members; however, due to the small number of HRC members, identification may become obvious over time.

Interviews were audio-recorded, with the exception of the interview with one HRC member who preferred not to be. In this case, the interviewer typed the participant's response. Interviews lasted no longer than one hour. At the completion of the interview, participants were thanked for their time and invited to join researchers to present the results. Audio-recordings were transcribed. Transcriptions were then analysed to identify themes in the methods for engaging community members.

\section{Findings}

Content analysis was used to interpret the qualitative data obtained from the open-ended questions asked during the interview. Both researchers served as coders and conducted an initial content analysis. Categories were developed to capture the themes expressed in the interviews. From here, categories were evaluated to ensure they accurately represented the content of the open-ended questions. If there was disagreement or confusion, researchers discussed the questions of origin and results until a mutual agreement was met (Neuendorf 2002).

Excluding questions capturing demographic information, participants were asked nine open-ended questions. These questions explored why they decided to become HRC members, what the purpose of the HRC was, their experience on the HRC, group dynamics and suggestions for growth. All participants responded to each question. To better understand why participants 
chose to become HRC members and what it was that enabled them to contribute their knowledge in the HRC setting, the responses to six questions will be reported on. These questions were: (1) How and why they decided to become a Hartland Resident Committee member; (b) What would they have done differently; (c) If and why people shared their ideas at HRC meetings; (d) Whether or not they felt they were heard at meetings; (e) If people who organised meetings helped people open up, and if so, how; (f) If they were facilitating HRC meetings, what they would do to help people open up. All participants responded to all questions asked. Themes from the responses to individual questions are reported below.

\section{This is my community!}

All members responded that they initially became involved as a result of their prior connection to the Hartland Partnership Center. Some people stated that, in addition to their initial connection to the Center, Hartland staff or friends recruited them to be on the HRC. From here, members were asked to expand on why they became HRC members. The response themes identified were: they wanted to support/help their community $(\mathrm{N}=5)$; they already worked/lived in the community $(\mathrm{N}=2)$; and they had personal or family history with the Center $(\mathrm{N}=2)$.

I decided to become a Resident Committee because, first of all, I've lived in [the neighboring apartments] ... and I started coming to the center when I was 16 and that is when I started translating for my mom and my dad. Seeing that throughout that many years ... made me want to continue, you know, doing the same work I did for my family for other residents at [the apartments] ... like using my language skills by helping others and stuff. (Fatima)

\section{Meaningful involvement}

When asked what he or she would have done differently, each participant shared a unique idea for the HRC. One participant shared that there was nothing she would have done differently, stating, 'I liked everything. I wouldn't change anything' (Nimo). Other responses were: visit other community organisations; maintain one cohort throughout the year; teach a class, and find more people to be involved on the HRC. When asked if there was anything he would have done differently at HRC meetings, one member spoke specifically to his own actions, stating, 'Not really except just try to respect one another. I know sometimes I act a little flashy ...' (Matt).

\section{Safe space and shared goals}

When asked if people shared their ideas at the meetings, all participants responded that people did tend to share their ideas. When asked why, we heard different responses from members. The themes we found were: facilitators shared experiences first $(\mathrm{N}=1)$; facilitators went around the table to ask for responses $(\mathrm{N}=1)$; facilitators called on people individually to respond $(\mathrm{N}=1)$; and people felt comfortable with being at a similar English level with the rest of the group $(\mathrm{N}=1)$. Finally, the most common reason why 
participants felt people shared their ideas at meetings was due to the fact that, although there were different cultures, everyone came together on one common goal $(\mathrm{N}=3)$ :

Everyone is sharing how the community can help everyone ... the main reason is because they all from different culture and find each other easy to get along with. Because the English level ... they were connected. They were all at the same level. (Sarura)

Everyone's from different cultures but everyone is one, so it's easier. It makes you more comfortable to share what you have in mind. (Nimo)

\section{Participatory action}

When asked if they felt their voice was heard at the meetings, most participants responded positively. One participant said that he felt his voice was heard most of the time, but felt like he was able to give feedback to the group about this. For those that responded positively, when asked why they felt this way, a few themes emerged. One person said the facilitator taking notes was an indicator that they were being listened to and heard $(\mathrm{N}=1)$. Participants also shared they felt they were heard because everyone was interested in hearing about and teaching their culture and personal experiences from the community $(\mathrm{N}=2)$. Finally, the most common reason why people felt their voice was heard was because they saw the suggestions they made being implemented $(\mathrm{N}=3)$. 'I do feel my voice is heard ... if I share ideas, like, the next few meetings ... I see what I've been sharing has been implemented. So that's why I felt I'm heard' (Fatima).

\section{Trusting and caring relationships}

The themes that emerged from how facilitators assisted participants with opening up were varied; however, all stated that facilitators had helped people engage in the meetings to share their thoughts or ideas. When asked how, the themes that emerged were that facilitators created a safe and respectful environment $(\mathrm{N}=2)$; checked in with group members at meetings $(\mathrm{N}=2)$; supported their endeavours and ideas $(\mathrm{N}=2)$; asked for feedback from the group $(\mathrm{N}=1)$; gave reminder calls to the group $(\mathrm{N}=1)$; hosted meetings at people's homes $(\mathrm{N}=1)$; brought people with different cultures together $(\mathrm{N}=1)$; provided food during meetings $(\mathrm{N}=1)$; and gave/ watched presentations $(\mathrm{N}=1)$.

Um, I like the ideas of whenever we start the meetings you started to like, ask by bringing up how are ... you really care. To me it means that you really care by going around and checking in with each one of us and how you doing. I like sharing what's going on with our life that moment. And usually, you can extend ideas of how you can help. If somebody like is going through something or they need help finding out on what they are going through ... that means a lot to me. That makes me comfortable by you guys doing that check-in first. That means you care about each one of us. (Fatima) 


\section{Participant engagement}

Responses to what methods HRC members utilised to assist with participant engagement ranged from offering positive interactions during meetings to providing an emotional component of respect and support for HRC members. The themes that emerged in response to the way participants would help people share ideas were to: give members time to talk about themselves during or outside of meetings $(\mathrm{N}=4)$; assign other members to facilitate meetings $(\mathrm{N}=1)$; make reminder calls $(\mathrm{N}=1)$; provide opportunities for members to 'better' themselves $(\mathrm{N}=1)$; provide food and snack $(\mathrm{N}=1)$; be yourself $(\mathrm{N}=1)$; be kind to members $(\mathrm{N}=1)$; and help individuals come to decisions on their own $(\mathrm{N}=1)$.

You welcome them. Smile, you say hi and say hello. Be kind. Be kind and smile warmly ... and stop to talk to people. Give people a chance to talk when you introduce yourself, and I think that will make them feel happy, and they will think, 'Oh, they are really welcoming me'. (Husna)

\section{DISCUSSION}

The data from these six questions came together to inform our understanding of how to engage HRC members to share their ideas and remain involved over time. Given that all participants had remained on the committee after the required one year, we hypothesised that participants felt their voice was heard and they were comfortable in their role as an HRC member. Participants did respond positively to all questions regarding their comfort sharing in the group.

Interviews with current and past HRC members revealed a range of ideas regarding why individuals felt comfortable sharing and engaging with the HRC and how they felt community members could be engaged. In support of the existing literature, responses reflected a value for the individual, the organisation and the community (Prestby et al. 1990). Individuals not only became a part of the HRC to give back to the community, but also to support the Center as an organisation. The responses reflected an individual connection created between committee members, which kept people engaged and sharing ideas at meetings. This connection created trust and friendship among members and developed into a comfortable environment - a space of belonging for HRC members to empower each other to be leaders in their community.

Gutierrez, DeLois and GlenMaye (1995) specifically identified methods that contribute to empowerment. These included building a relationship, facilitating the group process and building capacity. Easterling and Millesen (2012) also supported capacity building as a crucial element in empowerment of communities and individuals. The responses and identified themes from the sample of HRC members reflect these previous findings. For example, with regard to building a relationship, responses from HRC members 
highlighted the importance of facilitators actually caring about the lives of participants outside of the meeting space. Facilitating check-ins with the group created a space for individuals to discuss their communities and to provide support for those individuals and their community. In light of the capacity building aspect of empowerment, one member asked organisers to provide more leadership skill-building activities for members. And finally, with regard to facilitating the group process, members stated that tangible practices such as reminder calls and offering food contributed to a comfortable and open space, where they could discuss and share ideas.

The HRC members described the diversity of the group as a valuable tool in engaging community members and creating an engaging environment. As stated earlier, these six participants represented five different countries. All participants had lived in Salt Lake City for less than 16 years, with half of the participants living in Salt Lake City for less than 10. The cultural diversity spanned not only country of origin, but also length of time in Salt Lake City, individual values, age and gender. Diversity was described as a strength in two ways. First, one participant felt that the similar English abilities of all members created an inclusive environment for her. Second, individuals felt that, regardless of all of the cultural diversity in the group, their ability to come together on one common goal to aid the community created a safe space for them to share.

Gutierrez et al. (1996, p. 502) expanded on this definition of diversity to explain the process of multicultural organising: 'multicultural organizing ... recognizes and values the experiences and contributions of different social groups in an organization or community while working to bring groups together when necessary'. The HRC highlighted the importance of bringing their groups together to meet the needs of one community. Thus, the community shifts from separate groups to one shared space. The HRC meetings were described as a space that created an opportunity to build this space, leading to more engaged leaders in their community.

\section{CONCLUSION}

From this pilot study, we identified five methods that may create an open and engaging environment for local residents to serve as leaders in their community. First, provide opportunities for developing leadership skills. Second, create a kind and warm meeting space - an inclusive environment. Third, identify the common goal of the group while respecting diversity of individuals. Fourth, sincerely care about the members and their communities, both in the meetings and outside of the meetings. Finally, implement the decisions of the group members to the best of your ability.

While these interviews may be instrumental in guiding the direction of the HRC at the Hartland Partnership Center to empower community members as leaders, it is not without 
its limitations. This was a convenience sample and therefore may lend itself to sampling bias. The individuals who agreed to participate may have been more engaged members of the HRC and may have offered a different perspective on the process than someone who would not participate. Those conducting the interviews were also facilitators of the HRC meetings. Although the level of trust is high within the HRC, members may have felt pressure to respond positively to the questions asked. A randomised sample of individuals serving on leadership committees in other organisations in the area may generate a more generalisable list of recommendations for community empowerment and engagement.

Further research could be conducted with a larger sample to explore the differences in responses across ages. The youngest participant briefly remarked that her experience as a young community member participating in meetings with older adults challenged existing cultural norms for her. As this was beyond the scope of this study, we did not examine this further; however, we found this to be a common theme when informally discussing leadership roles with younger community members.

Future research could also explore the role of diversity in creating an inclusive space to share and engage as leaders in a community. This emerged as a theme, and contributes to our understanding of empowerment; however, the depth of the role and understanding of diversity could be explored further and greatly contribute to our understanding of creating engaging spaces for community leaders.

\section{ACKNOWLEDGEMENTS}

We'd like to acknowledge the Hartland Resident Committee, Hartland Partnership Center, and University Neighborhood Partners staff who supported us in this endeavour. We are especially grateful for the time from our committee members who participated in these interviews.

\section{REFERENCES}

Ayon, C \& Lee, C 2009, 'Building strong communities: An evaluation of a neighborhood leadership program in a diverse urban area', Journal of Community Psychology, vol. 37, no. 8, pp. 975-86.

Bourhis, R, Moise, L, Perreault, S \& Senecal, S 1997, 'Towards an interactive acculturation model: A social psychological approach', International Journal of Psychology, vol. 32, no. 6, pp. 369-86.

Cabezas, A, Reese, E \& Waller, M 2007, 'Introduction', in A Cabezas, E Reese \& M Waller (eds), The wages of empire: Neoliberal policies, repression, and women's poverty, Paradigm Publishers, Boulder, CO, pp. 3-15.

Crosby, L, Parr, W, Smith, T \& Mitchell, M 2013, 'The community leaders institute: An innovative program to train community leaders in health research', Academic Medicine, vol. 88, no. 3, pp. 335-42.

Easterling, D 2012, 'Scaling up civic leadership: Combining individuallevel change and culture change', National Civic Review, vol. 101, no. 4, pp. 51-64. 
Easterling, D \& Millesen, J 2012, 'Diversifying civic leadership: What it takes to move from "new faces" to adaptive problem solving', National Civic Review, vol. 101, no. 2, pp. 20-26.

Finn, J \& Jacobson, M 2003, 'Just practice: Steps toward a new social work paradigm, Journal of Social Work Education, vol. 39, no. 1, pp. 57-78.

Fraenkel, P 2006, 'Engaging families as experts: Collaborative family program development', Family Process, vol. 45, no. 2, pp. 237-57.

Farmer, P 2005, Pathologies of power: Health, human rights, and the new war on the poor, University of California Press Ltd, London, England.

Gray, M \& Webb, S 2009, 'Critical social work', in M Gray \& S Webb (eds), Social work theory and methods, Sage Publications, London, pp. 76-85.

Gutierrez, L, Alvarez, A, Nemon, H \& Lewis, E 1996, 'Multicultural community organizing: A strategy for change', Social Work, vol. 41, no. 5, pp. 501-08.

Gutierrez, L, DeLois, K \& GlenMaye, L 1995, 'Understanding empowerment practice: Building on practitioner-based knowledge', Families in Society, vol. 76, no. 9, pp. 534-42.

Hunter, R, Mai, T, Hollister, L \& Jankey, O 2011, 'A university-community partnership model for capacity-building and collective learning with individuals of immigrant and refugee experience: The example of the Hartland Partnership Center', Journal of Global Social Work Practice, vol. 4, no. 1, viewed 23 March 2014.

Hunter, R \& Mileski, K 2013, 'Emerging leaders project: Connecting university resources to community-based organizations supporting refugee resettlement', Advances in Social Work, vol. 14, no. 2, pp. 613-28.

Kegler, M, Norton, B \& Aronson, R 2007, 'Strengthening community leadership: Evaluation findings from the California Healthy Cities and Communities program', Health Promotion Practice, vol. 9, no. 2, pp. 170-79.

Kretzman, J \& McKnight, J 1993, Building communities from the inside out: A path toward finding and mobilizing a community's assets, Institute for Policy Research, Evanston, IL.

Mai, T \& Schmit, K 2013, 'Creating political and social spaces for transcultural community integration', in J Hou (ed.), Transcultural cities: Border crossing and placemaking, Routledge, New York, pp. 207-221.

Moll, L \& González, N 1997, 'Teachers as social scientists: Learning about culture from household research', in P Hall (ed.), Race, ethnicity and multiculturalism: Policy and practice, vol. 1, Garland Publishing, New York, pp. 89-114.

Neighborworks Salt Lake 2012, viewed 9 March 2013, www.nwsaltlake. org/community-building/20-westside-leadership-institute.

Neuendorf, K 2002, The content analysis handbook, Sage, Thousand Oaks, CA.

Prestby, J, Wandersman, A, Florin, P, Rich, R \& Chavis, D 1990, 'Benefits, costs, incentive management and participation in voluntary organizations: A means to understanding and promoting empowerment', American Journal of Community Psychology, vol. 18, no. 1, pp. 117-49.

University Neighborhood Partners 2014, viewed 2 January 2014, http:// partners.utah.edu/home. 
Wheatley, M \& Frieze, D 2011, Walk out walk on: A learning journey into communities daring to live the future now, Berrett-Koehler Publishers, Inc, San Francisco, CA. 